\title{
The Neurobiology of a New Idea - or The Death Instinct, Revisited
}

\section{Richard Brockman*}

Department of Psychiatry, Columbia University, College of Physicians and Surgeons, USA

\begin{abstract}
Stressed mice perseverate. Stressed humans perseverate. Freud described in what I had feel was his only true "science fiction thriller" - Beyond the Pleasure Principle - how traumatized patients perseverated, that is they persisted in repeating "un pleasure". It is I think rather unlikely that the "Death Instinct" is at the etiologic root of these behaviors for either mice or for men. Rather it may be stress and neural circuits that favor the locus ceruleus, the amygdala, and the dorsal striatum. And in order to impact these pathways, it may be necessary to intervene at the moment of anxiety. This paper describes just such active interventions at moments of anxiety - interventions informed by psychotherapy but very much expanding the boundaries of where and how psychotherapy should be done. The work is described with two patients both of whom persisted in repeating "unpleasure".
\end{abstract}

Keywords: Unpleasure; Repetition compulsion; Death instinct; Trauma; Dorsal striatum

\section{As a Resident there were Two Papers I read that Affected my Thinking Quite a Lot}

For a class in psychotherapy, I read Freud's "Beyond the Pleasure Principle" [1]. In the paper Freud expanded his formulation on a compulsion to repeat un-pleasurable experience, a drive that left those it afflicted as if possessed by some 'daemonic power', a power that seemed to doom its victim to a Sisyphean "recurrence of the same thing". To explain such a force, Freud was lead to the 'death instinct' - 'an inherent urge in organic life to restore an earlier state of things' an idea that seemed to warrant Freud's inclusion in the rarefied world of supernatural thinkers such as Jung, Skinner, and The Shadow. Freud was aware of how far he had gone. "What follows is speculation, often far-fetched..." He was aware that the further his speculations went 'the more untrustworthy' were his conclusions. He was also aware that one day biology would provide the data that would "blow away the whole of our artificial structure". It was as if he were telling the reader, "Follow my reasoning but not too closely because one day I will be proven wrong - and don't say I didn't warn you."

\section{The Other Paper I Happened upon by a Circuitous Route}

When I read a paper I admire, I often follow the references back to see where a writer began. It was through such a process of "travelling backwards" that I happened upon a paper by Mitchell, Osbourne, and O'Boyle - "Habituation under Stress" [2]. In it the authors described how traumatized mice repeatedly made most un-pleasurable choices even when they had alternatives. Briefly, a mouse was placed in the start box of a T maze. After 30 seconds in the start box, the door was opened and the animal was allowed to wander into one of the two goal arms. The control or "no shock' animal explored both the left and right goal arms alternating his/her selections over successive trials (there were a total of 10 trials) in a more or less random, exploratory manner. The subject or "shock animal", was placed in the start box where a foot shock was delivered for 30 seconds at which point the door was opened. What the authors discovered was that with each successive trial the shock animal perseverated - that is to say, the mouse chose the same goal arm as his/her initial choice with greater and greater consistency - even if the animal were re-shocked upon entering that particular goal arm. The no shock animals explored their options in successive trials they tended to alternate from one goal arm to the other. The shocked animals perseverated - they continued to pick the same goal arm even when that choice had bad consequences - and even when the experimental design encouraged alternation (the "Reinforce Alternation" design). The authors went on to say, "The present results constitute a replication of the repeated-testing preference shift from chance levels to perfect perseveration....Since the animals in the Reinforce Alternation perseverated more and more as the trials went by, they were actually increasing their exposure to shock trials". In other words, the "shock choice" mice kept making the same choice even when that choice lead to significant "un-pleasure". "If we take into account observations such as these," Freud wrote in 1920 as if prescient of Mitchell, Osbourne, and O'Boyle, "we shall find courage to assume that there really exist in the mind a compulsion to repeat which overrides the pleasure principle". I began to consider the idea that Freud may have been right.

I have treated some of these frustrating patients whose lives seem cursed by "the perpetual recurrence of the same thing". These are not necessarily patients suffering from the repetitive thoughts and rituals of obsessive compulsive disorder so much as those who keep making the same bad choice. "I know that what you are saying is true," Sara, a 45 year old woman suffering from bulimia nervosa agreed when I explained that binging and purging had been shown to lead to weight gain not loss - her stated goal. "I know. I know. But I also know that at one in the morning what you say won't matter because I know I will binge and purge the way I always do.” And I knew that she would. I knew that all the eating disorder experts, programs, hospitalizations, medications, peer groups and their support had been ineffective. I knew that my arguments and interpretations had also failed. I also knew that she was beginning to feel hopeless - a feeling that made its return more or less every six months, with its accompanying moons of suicidal urges and plans.

*Corresponding author: Richard Brockman, Associate Clinical Professor Department of Psychiatry, Columbia University, College of Physicians and Surgeons, USA, Tel: 212 496-1507; E-mail: rb37@columbia.edu

Received February 02, 2017; Accepted February 06, 2017; Published February 14,2017

Citation: Brockman R (2017) The Neurobiology of a New Idea - or The Death Instinct, Revisited. J Ment Disord Treat 3: 134. doi:10.4172/2471-271X.1000134

Copyright: () 2017 Brockman R. This is an open-access article distributed under the terms of the Creative Commons Attribution License, which permits unrestricted use, distribution, and reproduction in any medium, provided the original author and source are credited. 
I'm just waiting for night. That's how I feel. I never had a thought about the future being positive, not in my entire life, that there will be something to look forward to, that something might change. I don't see it. I never have. My day just seems to be an endless wait until night, when most people are asleep. That's when I start to prepare. When I take out the food. When I line it all up. When I feel calm. When nothing matters.

\section{Except When Hospitalized, Sara has binged and Purged Every Night for the Past 25 Years}

Rats that are subjected to caloric restriction will not overeat when allowed access to palatable food. However rats that are subjected to caloric restriction and then exposed to foot shock and given access to palatable food, "showed significant binge-like increases in caloric intake..." [3].

I was, I don't know, maybe 5, walking home from school and my mother was with me. I remember being in a good mood because I was with her - and she was flexing her hand back and forth, so I thought she wanted me to hold her hand. And so I reached out, but she pulled away and just kept flexing her hand. That was it. That's what I was remembering [4].

I had been treating another patient, Jessica, for affective disorder, depressed type, in the context of a masochistic personality structure. She was the eighth of her parent's eight children. Now in her mid 30's, single, well educated, an accountant. She presented with the chief complaint, "I have a hard time taking care of myself" - the abusive men she chose to take to her bed, the dangerous neighborhood where she lived, the amount she often drank, the unwanted pregnancies, the exploitation she seemed to encourage at work. She summed it all up - "I don't deserve any better." But there was one behavior that struck me as particularly odd. She has suffered from scoliosis since childhood with a more recent history of hairline stress fractures. She was diagnosed with osteoporosis - yet she refused any treatment - even to take Vitamin D as had been prescribed. "Why?" I naively asked. "I know I should take it," she affirmed, "I just don't."

I thought of Freud and his sense that people operating "beyond the pleasure principle" seemed "possessed by some daemonic power; but psychoanalysis has always taken the view that their fate is for the most part determined by infantile influences". I asked about "infantile influences" [5].

Jessica's grandfather had survived the Holocaust. Her mother had been abused by him for many years and according to the patient suffered from multiple personality disorder (dissociative identity disorder). "I'd come home from school and never know what I was going to find. Sometimes my mother was home quietly reading. Other times she'd be in a rage and beat us - especially me, mostly me." "Why you?" "Because the others wouldn't come home until late" [6].

As she spoke I thought of Mitchell, Osbourne, and O'Boyle's mice and the way they made the same choice. As she spoke I thought of Freud's extreme statement - "The aim of all life is death". I said "You were the sacrifice." She looked at me blankly. "You offered yourself as the lamb." She remembered being beaten - with a belt, a hanger, her mother's fists. "I would just stand there as she beat me." Her mother showed one of two extremes - indifference or rage. Her father, a lawyer, knew of his wife's "moods", but chose not to intervene. "If you want me to talk to your mother, I will. But it will end our marriage. Is that what you want?" She never asked him again [7].
Years later when her mother was dying of cancer, the patient withdrew from college to care for her. "Why?" "Because I felt sorry for her." "After what she had done?" "Yes." "Why?" "I don't know. Maybe I loved her. I guess I loved her.”

The session went back to broken bones, scoliosis, her refusal to take vitamin D. I interpreted that by not taking the vitamin she was keeping the relationship with her mother alive by internalizing 'bad parenting'. She agreed, thanked me for the insight, assured me she would stop her senseless behavior. When Jessica returned the following week, I inquired if she had been taking the vitamin D. "No," she replied, "I can't." "Why?" "I know what you are saying is true. But in the morning when I stand in front of the mirror, I feel nothing but hate." "Like you felt from your mother?" She just looked at me without responding, then said, "I can't take the vitamin D."

I began to rethink the pleasure principle and what lay "beyond". I was struck by the compulsion to repeat - in Sara, in Jessica, in the little boy whom Freud described compulsively playing a game that made a pull toy be - "gone". I went back to Mitchell, Osbourne, and O'Boyle. Were the mice suffering like Sara from a compulsion to repeat? Were they like the little boy struggling with some form of loss? Were they like Jessica, engaging masochistic choice? And if the answers to these questions were 'yes', was science ready to do more than give a phenomenological description of what it saw?

"We must be ready to abandon a path that we have followed for a long time, if it seems to be leading to no good end," wrote Freud at the end of his book. Was there a "drive" beyond the pleasure principle that science could identify other than what Freud had labeled as the drive for Death? [8]

My two patients; the example of Freud's little boy; Mitchell, Osbourne, and O'Boyle's mice; the binge eating rats - they had all been exposed to significant levels of ongoing stress - foot shock, loss of love, unpredictable violence, inconsistent mothering. From this observation I was lead to a new hypothesis - it is chronic stress, not the death instinct, that lies beyond the pleasure principle. It is chronic stress not the death instinct that changes one's relation to choice. It is chronic stress not the death instinct that dooms 'psychoanalysis' when the pleasure principle has been passed [9].

You can try to help me as much as you want, but I'll be walking down the street and these things will just come to my mind and everything shifts. And I'll remember I can't get better, I can't erase these feelings because these memories are always there, always ready to come back. And when they do, they overwhelm me.

The neurobiology of chronic stress changes the neurobiology of how a mammal - any mammal - remembers the past, predicts the future, acts in the present. Chronic stress fosters enduring changes in the mammalian central nervous system [10].

"In the theory of psycho-analysis," Freud wrote in the very first line of Beyond the Pleasure Principle, "we have no hesitation in assuming that the course taken by mental events is automatically regulated by the pleasure principle". But what Freud was getting at, and what I did not fully understand the first time I read those lines, was that beyond the pleasure principle analysis is doomed. The "daemonic power", which he derived from the death instinct and which science has shown to be the changed neurobiology of chronic stress, overwhelms it. Beyond the pleasure principle there is a qualitative change in the way mammals think.

I went back to Mitchell, Osbourne, and O’Boyle. I sought papers 
that cited their text. I followed those papers forwards and back. I was, as I said, impressed that shocked mice chose to repeat even when the choice lead to more shock. Under what conditions, I wondered, might they make another choice? How might one get a compromised mouse or woman or man or child to consider something new? How might one help a mammal when that mammal is under the compulsion to repeat? How might one help a "mental apparatus" when it is no longer guided by a 'principle' that, according to Freud, no longer seeks the reduction of pain?

By most accounts, stress initiates the action of multiple systems and loci in the mammalian brain - in particular the sympathetic nervous system, the locus ceruleus, the hypothalamic pituitary adrenal axis, the amygdala. Emotional arousal has been shown to affect not only how we register perception but also how we integrate perception - and when we integrate perception we are holding it up to memory.

Since the pioneering work of Scoville and Milner with their amnesiac patient HM (Henry Molaifson), it has been known that mammals have multiple memory systems. More recently it has been shown that not only do mammals have multiple memory systems, but that a given perception may be registered in multiple memory systems simultaneously. We can remember what we are told about tennis (hippocampal, declarative memory) as our back-hand improves from playing tennis (mostly dorsal striatal, implicit memory). Mammals don't remember in one system alone - and it has been shown that stress is one of the factors that determines which of the multiple memory systems predominates at a given moment in time.

To return to the work of Mitchell, Osbourne, and O'Boyle [2]. When calm, mice entered first one arm, then the other of the T maze - that is to say they chose freely amongst their options continuing over time to explore both arms of the maze. But when stressed, they increasingly made the same choice without regard to consequences. And they would make this same choice again and again and again. Mitchell, Osbourne, and O'Boyle explained their behavior as a fear of the new - "neophobia". A more complete explanation has since been uncovered.

When given a task that can be learned both "cognitively" by the hippocampus or "habitually" through stimulus-response learning of the dorsal striatum - a mammal will usually learn cognitively in the initial trials but with repetition, the learning shifts to the dorsal striatum ("Practice makes perfect" applies mostly to learning in the dorsal striatum). If a memory task is repeated often enough, one does not need to "think" too much about it. For example when first learning the path between one's home and school, one would have to "think about it" (hippocampus), but with time and repetition, the path becomes practically automatic (a shift to the dorsal striatum). Through repetition the dorsal striatum learns "patterns" - whether they are the muscle patterns of tennis (swinging at the ball), or the patterns of habitually chosen behaviors (the path home from school).

But it is not just repetition that favors the dorsal striatum. Stress also favors dorsal striatal learning. From an evolutionary perspective this makes sense. If when faced with an approaching tiger, those of our forebears who contemplated all possible options and outcomes - a hippocampal evaluation of the scene - probably died where they stood. On the other hand, those of our forebears who acted quickly in a stimulus-response manner through the dorsal striatum had a much better chance of survival. The hippocampal system by considering multiple options and outcomes against past experience makes a more careful evaluation, but such an evaluation costs energy, takes time.
The dorsal striatum by incorporating a stimulus-response appraisal, offers only one option based on past escape behavior, but does so quickly. Both systems involve the recall of memory. It's just that the one is contemplative, integrating many varieties of past experience while the other is impulsive referencing mostly only a replica of the current experience. The one is weighted towards a response based on new learning. The other is weighted towards a response that expends the least amount of work and takes the least amount of time based on the repetition of behavior that worked in the past - and the more often it worked, the more deeply is it rooted in the memory of the dorsal striatum.

What does this have to do with psychotherapy and in particular what does this have to do with Jessica and Sara, both of whom had been in multiple failed treatments and both of whom now seemed to be embarking on another treatment that seemed to be heading for failure only now with me? I wasn't sure, but I had a theory.

It is now well accepted that the extinction of learned associations - whether Pavlovian or stimulus-response learning - is not about the eradication or an old memory but rather about new learning. And further that the new learning in order to effectively override the old must occur in or act on the system in which the original memory had been lain down. So in order to extinguish a Pavlovian association that had been learned through the amygdala, would require new learning to occur in or act on the amygdala.

Both treatments were treading water at best. I felt that there was in each case a positive, idealizing transference. I felt that the affective component in each had been adequately treated psychopharmacologically. I felt that in many respects both patients were much improved except for core issues - Sara's bulimia and Jessica's masochism. In other words, I could pretend that these treatments were successful on limited criteria but basically they were both failing.

I decided that the psychotherapy I was doing was failing because the psychotherapy I was doing was largely on one side of the pleasure principle while the psychopathology I needed to affect was largely on the other side. I decided that the psychotherapy I was doing was failing because I was addressing the hippocampal memory system while the psychopathology was largely residing in the overall stress response, in the amygdala and in the dorsal striatum. And so I decided that if the psychotherapy I was doing with these two patients were going to affect their core psychopathology, it would have to change rather drastically.

In my office when sitting across from me, both patients saw the wisdom of my words, "I know what you are saying is true," both had said. But both had also said that when alone with themselves, what I had said didn't matter. Something else took over. My speculation was that at that moment, or in the moments leading up to it, both women had felt a deep sense of loss - "Loss of love and failure leave behind a permanent injury to self-regard which contributes more than anything to the sense of inferiority". From such a place of loss comes a deep sense of abandonment and fear and then something else, something changes - "I know that what you are saying is true," Sara, said. "But I also know that at one in the morning what you say doesn't matter." "I know what you are saying is true," Jessica said, "But when I stand in front of the mirror, I feel nothing but hate." Both of these women were describing something rather remarkable. They were describing the moment when their thinking qualitatively changed.

When stressed, there is a shift of pathways in the central nervous system. When stressed, perception is preferentially routed through the amygdala and if the stressor is habituated - that is to say, if the stressor 
is not just feared but also familiar (if like a habit, it is known) - then there is a facilitation of input through the (basal lateral) amygdala to the dorsal striatum. Further there is an inhibition of input to the hippocampus. Thus stress has been shown to enhance dorsal striatal learning and recall at the same time that it has been shown to inhibit hippocampal learning and recall - all of this happening without awareness. "It is unlikely that stressed individuals make a conscious decision to abstain from cognitive solutions and opt for a habit leaning strategy. Rather stressed human subjects may rely on their habit system simply because the available cognitive solutions go unnoticed" [4].

("I know that what you are saying is true. But I also know that at one in the morning what you say doesn't matter.")

Something happens when the brain shifts 'beyond the pleasure principle' that essentially invalidates conventional psychotherapy. My argument is that there is a shift brought on by acute anxiety/stress in the context of chronic anxiety/stress - that facilitates habit-based memory and recall at the expense of cognitive-based memory and recall. And thus at that time, psychotherapy fails because psychotherapy by and large does not 'speak' to habit-based learning systems but rather it 'speaks' to the brain's cognitive-based learning systems. New learning (extinction) based in the hippocampus will have little or no effect on old learning based in the dorsal striatum. Thus I decided that if these treatments were going to succeed, I would have to find a way to 'speak' to habit-based learning in the dorsal striatum.

"I want you to do breathing exercises - five deep breathes every hour." "Why?" "I also want you to text me every morning." "Why?" "Because then I will know that you are awake and I will call you, and we will talk as you stand in front of the mirror with the bottle of vitamin D in your hand." "That's too weird. I can't do that." "We will start tomorrow morning." It wasn't exactly like that - but almost.

I should also add the dozens of caveats, disclaimers, thoughts of malpractice lawyers. But I will pass over all that. I will just mention that the nature of the transference and the trust between these patients and myself came after a long psychotherapeutic process - what followed could not have been done without that in place.

When I met with Sara, I outlined a similar plan. She was to do breathing exercises - five slow deep breathes every hour and as needed whenever she felt her anxiety picking up. She was to text me whenever she found herself thinking about food. "Why?" "Because whenever you are thinking about food you aren't really thinking. Rather you are allowing a habituated path of anxiety to gain strength. That is exactly when you need to stop 'thinking' and breathe." "That makes no sense." "No, it is your thinking that makes no sense. You are going to have to accept that whenever you think about food your anxiety increases and your brain pretty much stops being able to think." I explained a little about the amygdala, the dorsal striatum, the hippocampus (and a little about the ventral striatum and the aberrant reward system in bulimic food junkies as well). "Whenever you find yourself 'thinking' - stop, and text me." I also told her that late at night, just before she starts preparing a binge, taking out the food, lining it all up - that she should text me and if I were awake [2], I would call her back. "You want me to call you at midnight?" "I want you to text me before you start sliding into a binge. And then I will call you." "Every night?" "Every night." "That's too weird." "We'll start tonight."

When "mental events" are no longer regulated by the pleasure principle, then psychotherapy must be modified. The treatment must be redesigned depending on what part of the central nervous system needs to be reached.
Two weeks after daily texts and calls to Jessica, we switched to my returning her calls twice a week. Then once a week. After a month she is taking her vitamin D. She texts me every day.

I reply only by text. She is doing the breathing exercises as prescribed. Other aspects of her masochistic character have not been addressed, not yet. Getting her to take care of herself so far is being done little by little, step by step, one pill at a time.

\section{Conclusion}

Treating Sara's bulimia has been more difficult. Bulimia nervosa has the added complication of addiction and its compromised reward system. There is also the issue of shame. Despite that, Sara has reduced the number of binges and purges from a daily ritual to where she is now - two or three per week. She texts me during the day, and again at night. I call her back - usually around midnight. We talk for usually about 4 or 5 minutes.

There are all kinds of issues that you must be wondering about this treatment - and perhaps about me. All I can say is that one has to start somewhere and science might very well be on my side.

When Freud addressed the problem of "the recurrence of the same thing" he was lead to invoke "daemonic powers" acting on behalf of the "death instinct". Beyond the pleasure principle was a state of mind - and brain - where nothing new was allowed, 'an inherent urge in organic life to restore an earlier state of things' - dust.

And so to return to a new idea - the neurobiology of a new idea isn't really about the generation of new ideas at all. It is about the freedom to choose. The task for 'therapy' is then no different from the task that Freud had established for psychoanalysis all along - the removal of resistance. It's just that beyond the pleasure principle, resistance has undergone a biological change (which as Freud had predicted blows away a good many of our hypotheses). This resistance does not reject new ideas because of their content ("the ostrich policy - in a word the memory stinks"). Rather new ideas do not become conscious because the cognitive system from which they have been spawned have lost the battle for access.

\section{References}

1. Freud S (1975) Beyond the Pleasure Principle. In: Strachey J (ed.) The standard edition of the complete psychological works of Sigmund Freud London, Hogarth Press 18: 3-64.

2. Mitchell D, Osborne EW, O'Boyle MW (1985) Habituation under stress Behavioral and Neural Biology 43: 212-217.

3. Mathes WF, Brownley K, Mo X, Bulik C (2009) The biology of binge eating Appetite 52: 545-553.

4. Packard MG, Goodman J (2012) Emotional arousal and multiple memory systems. Frontiers in Behavioral Neuroscience 6: 1-9.

5. Gabriele A, Packard MG (2006) Evidence of a role of multiple memory systems in behavioral extinction. Neurobiology of Learning and Memory 85: 289-299.

6. Packard MG (2009) Anxiety, cognition, and habit. Brain Research 1293 121-128.

7. Poldrack RA, Packard MG (2003) Competition among multiple memory systems. Neuoropsychologia 41: 245-51.

8. Sara SJ (2009) The locus ceruleus and noradrenergic modulation of cognition Nature Reviews Neuroscience 10: 211-222.

9. Schwabe L, Wolf OT (2013) Stress and multiple memory systems. Trends in Cognitive Sciences 17: 2 60-68.

10. Schwabe L, Wolf OT (2009) Stress prompts habits in humans. Journal of Neuroscience 29: 7191-7198. 